\title{
There Is Truth And Beauty In Undergraduate Mathematics Research
}

\author{
Dele Oluwade \\ Editor in Mathematics and Computational Sciences \\ Senior International Editor \\ American Journal of Undergraduate Research \\ Dewade Science Clinic \\ Ibadan, Oyo State NIGERIA
}

\begin{abstract}
The famous mathematician, philosopher and 1950 Nobel Literature laureate Bertrand Arthur William Russell (1872-1970) once wrote that 'Mathematics possesses not only truth, but supreme beauty, a beauty cold and austere like that of sculpture'. This disciplineMathematics-is also fondly and widely regarded as the 'queen' and 'servant' of the sciences. The truth in mathematics can be likened to its scientific nature whilst its beauty is synonymous to its artistic or humanistic flavor.

Mathematics research at the undergraduate level has the potential of stimulating a refreshing 'environment' as well as serving as a form of hobby. However this potential can only be practically realized if the student masters some of the basic intrinsic and extrinsic 'tricks' inherent in mathematics research. Of course, there is the likelihood that a person who has been motivated for mathematical excellence from high school would find the research enterprise more enjoying than one who developed hatred for the discipline right from high school!

For instance, the primary motivation which this writer derived from the heaps of notebooks containing mathematical problems and exercises which he solved during high school (and during the few immediate succeeding months after the completion of the final high school external examination) provided the motivation to compile and reorganize the notebooks into a book project whilst on a summer students
\end{abstract}

industrial training program as a Year III undergraduate student of Engineering and Technology. This later provided the impetus boldness and confidence for him to completely change his course of study and register fully as a Bachelor's degree student of Mathematics!! That is, his initial research 'explorations' in high school provided the confidence to overlook the risk involved in such a change of course in a highly unpredictable and underdeveloped nation!!!

Historically, Mathematics has been broadly divided along the line of Pure Mathematics and Applied Mathematics, though there is increasingly a thin line of demarcation between these broad divisions in the present technological age. Applied Mathematics incorporates all forms of application of Mathematics in other fields including Statistics, Computer Science, Engineering, Medicine, Physics, Chemistry, etc. The scope of application of Mathematics is indeed limitless!!!!

The results of Mathematics are arrived at through a step-by-step logical procedure based on known facts called axioms. (Pure) Mathematics results are frequently formulated in terms of theorems and their proofs. The method of proof for solving a typical mathematical problem depends on the nature of the problem. Some of the standard popular methods of proof in Mathematics are mathematical induction, deduction, proof by contradiction, proof by counterexample and 'proof by hypothesis'. In particular, the proof by hypothesis is frequently used in Topology 
when proving the equivalence of two statements about a topological space. To prove that $x$ implies $y$ using this method, one starts with a hypothesis of $y$, converts it to a hypothesis of $\mathrm{x}$, then applies or manipulates $x$ so that the conclusion of $y$ will follow thereafter.

A Pure Mathematician does not really need to bother himself/herself about the applicability of his/her results. What is important is the consistency and logicality of his/her theorems. As is often the case, someone somewhere and someday would invariably find ways of applying the theorems to some (real-life) problems. This has been the situation in several instances even with respect to highly abstract mathematical theorems in which the possibility of their applications was never imagined.

One must not fail to mention in this article especially for the benefits of undergraduates in underdeveloped or developing countries the interesting case of Srinivasa Ramanujan (1887-1920), the famous self-tutored Indian mathematician of the number theory fame who was the first citizen of the developing nations of his time to be awarded the prestigious fellowship of the Royal Society, London- reputed to be the highest scientific body in Britain and one of the most prestigious honorific societies in the world. The main lesson in the life of this great mathematician is that despite the limitations, hardships and lack of a conducive environment in developing nations, a determined, focused and hardworking young mathematician can still make his/her impact on the global intellectual scene.

We end this article by throwing open the following exercises, answers to which may be sent by undergraduate readers of this journal to deleoluwade@yahoo.com. The answers could either be a full reference to a journal/book where the proofs could be directly found or well laid out raw proofs of the exercises. The exercises are as follows:

Prove or disprove that (a) the addition of two transcendental/irrational numbers is transcendental/irrational; and that (b) the product of two transcendental/irrational numbers is transcendental/irrational.

Welcome to the exciting world of undergraduate mathematics exploration and research-the discipline of truth and beauty!!!!

\section{Subscribe to the American Journal of Undergraduate Research}
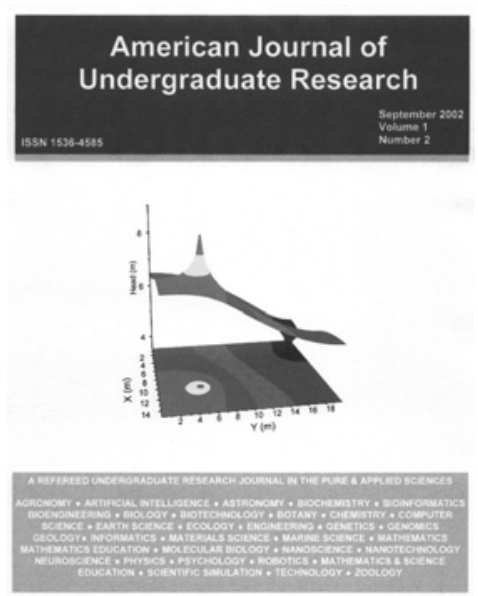

Individual Rate: Institutional Rate: \$40/year

Back Issues available at $\$ 5 /$ issue
AJUR Subscriptions Physics 205
University of Northern lowa
Cedar Falls, lowa 50614-0150 USA
Cheques payable to "AJUR"
Institutions will be invoiced. 